acids are cut out and refluxed in a reaction mixture consisting of $4 \mathrm{ml}$. of ninhydrin solution and $0.2 \mathrm{ml}$. of EDTA solution and $0.1 \mathrm{ml}$. of water.

The method has been so far successfully employed for the determination of amino acids in ether-treated trichloroacetic acid and warm-water extracts of yeast cells (Benziman, 1956) and for following the enzymic decomposition of polylysin (M. Rigbi, personal communication).

\section{SUMMARY}

1. The coloured reaction product of amino acids with ninhydrin (ANP) was prepared in the solid state. Extinction coefficients for its absorption maxima at 578 and $408 \mathrm{~m} \mu$ were determined.

2. By using the fact that ANP is greatly stabilized in the presence of ethylenediaminetetra-acetic acid, uniform absorption spectra are obtained and oxidative side reactions leading to the decomposition of ANP are avoided.

3. The $\alpha$-amino nitrogen of amino acids is quantitatively transferred to ANP.

4. The changes in the reactivity of ninhydrin with amino compounds in different ethanol-water mixtures and in aqueous solutions at different $\mathrm{H}^{+}$ion concentrations, and the accompanying changes in its absorption spectrum, are explained by structural changes in the ninhydrin molecule.
A structure for the reactive form of ninhydrin and hydrindantin is suggested.

5. An analytical method for the spectrophotometric determination of $0.5-6 \mu \mathrm{g}$. of $\alpha$-amino nitrogen, contained in amino acids or peptides, is described.

The author wishes to express his gratitude to Professor A. Neuberger, F.R.S., for helpful advice and discussions.

\section{REFERENCES}

Benziman, M. (1956). Ph.D. Thesis: The Hebrew University, Jerusalem.

Clarke, H. T. (1948). Organic Chemistry, 2nd ed., vol. 2, p. 1049. Ed. by Gilman, H. New York: Wiley.

Gomberg, M. \& Bachmann, W. E. (1927). J. Amer. chem. Soc. 49, 236.

Grassmann, W.\& Arnim, K. v.(1934). Liebigs Ann. 509, 288.

Kay, R. E., Harris, D. H. \& Entenman, C. (1956). Arch. Biochem. Biophys. 63, 14.

McFadyen, D. A. (1948). J. biol. Chem. 153, 507.

Moore, S. \& Stein, W. H. (1948). J. biol. Chem. 176, 367.

Moubasher, R. \& Ibrahim, J. (1949). J. chem. Soc. p. 702.

Ruheman, J. (1911). J. chem. Soc. 99, 797.

Schönberg, A. \& Moubasher, R. (1949). J. chem. Soc. p. 212.

West, E.S. \& Rinehart, R. E. (1942). J.biol. Chem. 146, 105.

Wheland, G. W. (1953). Advances in Organic Chemistry, 2nd ed., p. 717. New York: Wiley.

Wieland, T. (1949). Fortschr. chem. Forsch. 1, 211.

Woker, G. \& Antener, I. (1937). Helv. chim. acta, 20, 1260.

Yanari, S. (1956). J. biol. Chem. 220, 683.

\title{
Blood Lipids
}

\section{PLASMA LIPIDS OF THE LACTATING COW: CHROMATOGRAPHY ON SILICIC ACID}

\author{
By G. A. GARTON AND W. R. H. DUNCAN \\ Rowett Research Institute, Bucksburn, Aberdeenshire
}

\section{(Received 13 March 1957)}

Arteriovenous studies (for review see Folley, 1956) have demonstrated that no component of blood lipids except triglycerides and possibly cholesterol esters is absorbed from the blood plasma by the lactating ruminant udder. It is therefore of some importance to study the fatty acid composition of these classes of lipid, though it is first necessary to separate them from each other and from other plasma lipids.

The separation of mixtures of lipids into their component classes was restricted for many years to their segregation into acetone-insoluble lipids (phospholipids) and acetone-soluble lipids (glycerides, sterol esters, free sterols and fatty acids), from which mixture the last two components could each be recovered chemically. However, no means of distinguishing between fatty acids in combination as glycerides and as sterol esters was devised until Kelsey (1939) used pig pancreatic lipase for the selective hydrolysis of glycerides in the presence of cholesterol esters. This procedure was employed by Kelsey \& Longenecker (1941) in an investigation of the component fatty acids of the plasma lipids of lactating cows. As has been discussed by Lovern (1956), it seems that the enzymic procedure is unsatisfactory in that it does not effect the complete hydrolysis of glycerides. Clément, ClémentChampougny \& Louedec (1954) found that the method given by Kelsey (1939) did not effect more than $67 \%$ hydrolysis of the glycerides from various 
animal sources, including dog and rabbit serum. This finding is in accord with the studies of Desnuelles, Naudet \& Rouzier (1948) and Savary \& Desnuelles (1956) on the hydrolysis of triglycerides by pig pancreatic lipase in vitro.

In the present study the more recently developed technique of adsorption on silicic acid followed by selective elution (Fillerup \& Mead, 1953a) was successfully employed to separate the classes of lipids present in extracts of the plasma of lactating cows with particular reference to the sterol esters and triglycerides. A preliminary account of part of this work has been published (Lough, Garton \& Duncan, 1957).

\section{EXPERIMENTAL}

Solvents. Absolute ethanol (B.P. 1948) and methanol (A.R.) were used as supplied by J. Burrough Ltd., London, S.E. 11. Light petroleum (b.p. 40-60 ${ }^{\circ}$ was of A.R. grade (British Drug Houses Ltd.). Ether was dried and rendered free from peroxides immediately before use by distillation over $\mathrm{KOH}$ and reduced iron.

Analytical methods. Iodine values were determined by the semi-micro method of Trappe (1938). Phosphorus was estimated according to Berenblum \& Chain (1938) after wetashing (with $\mathrm{H}_{2} \mathrm{SO}_{4}$ ) of the lipid; lipid $\mathrm{P}$ was satisfactorily estimated in egg lecithin with this ashing procedure. A solution of the lipid in $\mathrm{CHCl}_{3}$ was taken for the spectrophotometric determination of carotene, the reference value $E_{1}^{1} \%$ at $463 \mathrm{~m} \mu=2200$ (Morton, 1942) being used. Free fatty acids, and possibly other acidic lipids, were estimated by titration of a solution of lipid in ethanol-benzene (1:1, $\mathrm{v} / \mathrm{v}$ ) against methanolic $0.01 \mathrm{~N}-\mathrm{KOH}$, with bromothymol blue as indicator. Titration was difficult owing to the orange colour of the solutions, and the values given (Table 1) are approximations, erring on the high side. Free and ester cholesterol were determined essentially according to Schoenheimer \& Sperry (1934); satisfactory recovery of authentic cholesterol and cholesterol from cholesterol palmitate was obtained. Glycerol was determined by the method of Lambert \& Neish (1950) as modified by Korn (1955); glyceride fatty acids were determined by titration of the acids isolated from hydrolysates.

Blood samples. Blood was obtained at the Aberdeen slaughterhouse from the jugular vein of a 3-year-old lactating Ayrshire cow and by jugular venepuncture from each of six lactating Ayrshire cows (aged 3-13 years) of the Duthie Experimental Stock Farm herd of this Institute. The blood was taken into saturated sodium citrate solution $(20 \mathrm{ml}$./1. of whole blood) and centrifuged as soon as possible to obtain the plasma. From the slaughtered animal, subsequently referred to as cow 1, $2740 \mathrm{ml}$. of plasma was obtained. From each of the living animals (cows 2-7) about $500 \mathrm{ml}$. of plasma was obtained; before further treatment the plasma was pooled to give a total of $2740 \mathrm{ml}$. The plasma volumes given above have been 'corrected' for their content of citrate solution.

Diets of cows. Cow 1, which had been fasting for $12 \mathrm{hr}$. when the blood sample was taken, was previously fed on a diet consisting mainly of turnips, silage and concentrates. Cows 2-7 had been pasture-fed for 4 weeks.
Treatment of plasma. The plasma was poured slowly, with shaking, into 2 vol. of ethanol and allowed to stand for 1-2 hr. at room temperature. The precipitated protein (containing most of the lipids) was filtered and the filtrate concentrated to about $250 \mathrm{ml}$. in vacuo in an atmosphere of $\mathrm{N}_{2}$. The concentrate was extracted with $3 \times 100 \mathrm{ml}$. of light petroleum-ether $(1: 1, v / v)$. The extract was dried over anhydrous $\mathrm{Na}_{2} \mathrm{SO}_{4}$, filtered and combined with the lipidcontaining extracts of the precipitated protein (see below).

The protein 'cake' was dispersed in ethanol-ether (3:1, $\mathrm{v} / \mathrm{v}$ ) in the proportion of $1 \mathrm{l}$. of solvent/l. of original plasma. The mixture was refluxed on a water bath for $4 \mathrm{hr}$. and then filtered at the pump. Extraction of the protein was repeated twice and after the third extraction the protein 'cake' was dispersed in hot ethanol-ether and thoroughly washed on the filter with hot solvent. The combined ethanol-ether extracts were concentrated to about $250 \mathrm{ml}$. on a water bath under reduced pressure in an atmosphere of $\mathrm{N}_{2}$. At this stage the concentrated extract became cloudy, suggesting that water present was rendering some of the lipid insoluble. The concentrated extract (lipids plus aq. ethanol) was extracted with $6 \times 100 \mathrm{ml}$. of light petroleum and the solution was dried over anhydrous $\mathrm{Na}_{2} \mathrm{SO}_{4}$. After filtration most of the solvent was removed before the extract was combined with the light petroleum-ether solution of lipid derived, as explained above, from the aq. ethanol filtrate of the precipitated plasma proteins. The solvents were finally removed to yield, in each case, a viscous, orange-red oil which was stored under $\mathrm{N}_{2}$ at $-1^{\circ}$ in the dark for a few days until the chromatographic examination was begun. The yields of lipid and some of their analytical characteristics are shown in Table 1. No watersoluble free fatty acid was present in either of the lipid preparations.

Preliminary experiments on chromatographic separation of lipids. Before silicic acid of American origin, as used by Fillerup \& Mead (1953 $a, b)$, Mead \& Fillerup (1954) and Borgström $(1952 a, b)$, was successfully employed (see below) several silica-gel preparations were examined in conjunction with various eluting solvents, including those recommended by Mead \& Fillerup (1954). The silica-gel samples used were (1) prepared from water glass in 1947 by Dr R. L. M. Synge in the same way as described for silica gel ' $\epsilon$ ' (Gordon, Martin \& Synge, 1944); (2) made by Dr P. J. Heald in 1950 from water glass according to Gordon, Martin \& Synge (1943); (3) prepared from 'silicic acid' (British Drug Houses Ltd.) by heating at $120^{\circ}$ for $24 \mathrm{hr}$. followed by grinding and sieving through a 160-mesh B.S. sieve. Slurries in light petroleum, prepared from gels 1 and 2 before and after heating at $120^{\circ}$ for $24 \mathrm{hr}$., and from gel 3, were introduced into glass tubes to form columns $7 \mathrm{~cm} . \times$ $\mathbf{2 . 5} \mathrm{cm}$. Silica gel 3 and gel 2 before or after heat treatment

\section{Table 1. Amounts of plasma lipids extracted and their general analytical characteristics}

Cow 1 Cows 2-7 (2740 ml.) (2740 ml.)

Lipids extracted (g.)

Lipids (mg./100 ml. of plasma)

Iodine value

Acidity (as oleic acid, \%)

Carotene $(\mu \mathrm{g} . / 100 \mathrm{ml}$. of plasma)

Phosphorus (mg./100 g. of lipid)

$\begin{array}{cc}6 \cdot 07 & 6 \cdot 69 \\ 221 & 244 \\ 99 \cdot 0 & 115 \cdot 5 \\ 1 \cdot 9 & 0 \cdot 9 \\ 616 & 1216 \\ 7 & 82\end{array}$


offered considerable resistance to the flow of light petroleum or methanol even when 'positive' pressure was applied; the flow-resisting properties were not greatly altered when Hyflo Super-Cel (Johns Manville, London, S.W. 1) was previously mixed with the gels in proportions of up to $1: 3$ $(w / w)$. Trials with these samples were therefore abandoned, as were trials with silica gel 1 , which although it gave convenient flow rates, failed to adsorb any lipid applied in solution in light petroleum.

A small sample of silicic acid (Baker Chemical Co.) which had been heated to $120^{\circ}$ for $24 \mathrm{hr}$. was obtained through the courtesy of Dr B. Borgström (University of Lund, Sweden) and this was found to give a suitable flow rate with light petroleum when mixed with 0.4 of its weight of $\mathrm{Hyflo}$ Super-Cel. When applied to the column in amounts of about $30 \mathrm{mg}$. of lipid/g. of adsorbent (cf. Borgström, 1952b) effective separation was achieved of artificial mixtures of two or more of the following lipids: cholesterol palmitate (British Drug Houses Ltd.), lard triglycerides [purified by crystallization at $-10^{\circ}$ from a $10 \%(\mathrm{w} / \mathrm{v})$ solution in acetone], cholesterol (British Drug Houses Ltd.; m.p. $146^{\circ}$ ) and egg-yolk phospholipids (prepared by repeated acetone precipitation from fresh-yolk lipids). No lipid was eluted with light petroleum alone; light petroleum containing 1,3 and $10 \%(v / v)$ of ether was employed to elute successively cholesterol palmitate, lard glycerides and cholesterol. Phospholipids were subsequently eluted with ethermothanol (3:1, v/v). When palmitic acid (British Drug Houses Ltd.) was included in the mixtures it could not be separated effectively from triglycerides by employing successively 3,4 and $5 \%$ of ether in light petroleum as the eluting solvent (cf. Mead \& Fillerup, 1954).

\section{RESULTS}

\section{Chromatographic separation of plasma lipids}

A large batch of silicic acid powder ('Baker Analysed' Reagent, J. T. Baker Chemical Co., Phillipsburg, U.S.A.) was obtained; before use it was thoroughly washed with hot methanol, warm ether and warm acetone and activated at $120^{\circ}$ for $24 \mathrm{hr}$. Hyflo Super-Cel was stirred with a large volume of water and the fine suspended particles which did not settle within $1 \mathrm{hr}$. were removed by suction; it was then washed by solvents and heated as described for silicic acid. Both the silicic acid and the Hyflo Super-Cel were stored in full, sealed bottles until used. The successful preliminary experiments with this brand of silicic acid were repeated with material from the large batch. Largescale separations were then carried out with $5 \cdot 60$ and $5.58 \mathrm{~g}$. respectively of the plasma lipids from cow 1 and cows 2-7.

For each separation a slurry of a mixture of silicic acid (200 g.) and Hyflo Super-Cel (70 g.) was made in light petroleum and the mixture was heated to boiling on a water bath to expel dissolved gases. The slurry was rapidly transferred to a glass tube with gentle tamping to give a column $21 \mathrm{~cm} . \times 5.5 \mathrm{~cm}$. supported on a thin layer of cotton wool on a porcelain-filter disk. The lipid, in solution in light petroleum $(20 \mathrm{ml}$.$) , was then carefully$ applied to the column with a pipette and elution with light petroleum was started, followed successively by 1,3 and $10 \%(v / v)$ of ether in light petroleum and ending with ether-methanol $(3: 1, v / v)$. Fractions each of $750 \mathrm{ml}$. of eluate were collected and the solvent was removed under reduced pressure; each eluting solvent was used until it practically ceased to bring any further lipid off the column. As a further check on the progress of elution, the lipid fractions were submitted to the Liebermann-Burchard reaction as indicated in Fig. 1. From the lipids of cow 1, 52 column fractions were collected, and 48 from the lipids of cows 2-7.

The elution pattern was very similar in each case; that for the plasma lipids of cows 2-7 is shown in Fig. 1. The recoveries from the columns were $\mathbf{9 8 . 4}$ and $\mathbf{9 7 . 7} \%$ respectively for the plasma lipids of cow 1 and cows 2-7. Four main peaks were obtained from each sample of total lipids, and from the work of Fillerup \& Mead (1953 $a, b)$, Mead \& Fillerup (1954) and our own preliminary studies it was concluded that these represented sterol esters, glycerides (together with any free fatty acids), free sterols and phospholipids. In addition, traces of lipid, possibly hydrocarbons (cf. Lovern, 1956), were eluted with the solvent front and the sterol esters were followed off the column by very small amounts of lipid, the exact nature of which remains to be determined. Appropriate fractions were combined to give the components shown in Table 2, in which certain analytical characteristics of the lipids are also recorded.

At room temperature, fractions $A$ were colourless, soft and waxy, fractions $B$ were viscous, deep-red oils which crystallized on standing, fractions $C$

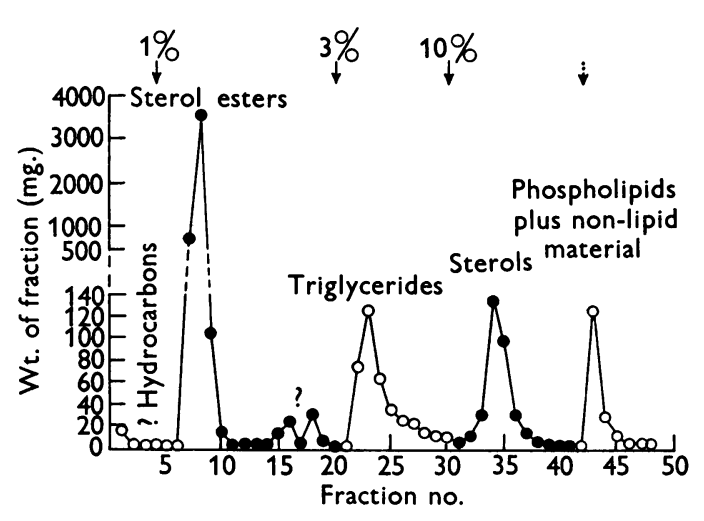

Fig. 1. Chromatography on silicic acid of plasma lipids from cows 2-7. Changes in eluting solvent $(1,3$ and $10 \%$ of ether in light petroleum) are indicated by arrows; broken arrow indicates change to ether-methanol (3:1). $O$, Negative Liebermann-Burchard reactions; $\bigcirc$, positive Liebermann-Burchard reactions. 


\section{Table 2. Amounts of analytical characteristics of pooled chromatographic fractions}

Amounts of lipid chromatographed are given in parentheses. A dash indicates not determined, but probably negligible; (0) indicates none detected.

Designation
of lipid
fraction

A ? Hydrocarbons

$B \quad$ Sterol (cholesterol) esters

$C \quad$ Contains sterol esters

D Triglycerides plus a little

free fatty acid

$\boldsymbol{E} \quad$ Sterols (cholesterol)

F Phospholipids plus non-

lipid material

$$
\begin{aligned}
& \text { Pydrocarbons } \\
& \text { Sterol (cholesterol) esters } \\
& \text { Contains sterol esters } \\
& \text { Triglycerides } \\
& \text { Sterols (cholesterol) } \\
& \text { Phospholipids plus non- } \\
& \text { lipid material }
\end{aligned}
$$

\begin{tabular}{|c|c|c|c|c|c|}
\hline \multirow{2}{*}{$\begin{array}{l}\text { Column } \\
\text { fractions } \\
\text { pooled }\end{array}$} & \multirow{2}{*}{$\begin{array}{l}\text { Wt. of } \\
\text { lipid* } \\
\text { (g.) }\end{array}$} & \multirow{2}{*}{$\begin{array}{l}\text { Percentage } \\
\text { of total } \\
\text { lipid } \\
\text { recovered }\end{array}$} & \multirow{2}{*}{$\begin{array}{l}\text { Iodine } \\
\text { value }\end{array}$} & $\begin{array}{l}\text { Cholesterol in } \\
\text { fraction }(\%)\end{array}$ & \multirow{2}{*}{$\begin{array}{l}\text { P content } \\
\text { (mg./100 g. } \\
\text { of fraction) }\end{array}$} \\
\hline & & & & & \\
\hline
\end{tabular}

Cow 1 (E.60 g.)

$\begin{array}{ccrrccc}1-6 & 0.03 & 0.4 & 10.6 & - & - & \text { - } \\ 7-12 & 3.64 & 65.8 & 120.3 & (0) & 62.5 & = \\ 13-16 & 0.07 & 1.0 & 93.2 & (0) & 43.2 & -1.0 \\ 17-31 & 1.02 & 18.5 & 41.0 & (0) & (0) & (0) \\ 32-44 & 0.65 & 11.8 & 68.9 & 89.8 & (0) & 20 \\ 45-52 & 0.14 & 2.5 & 94.5 & - & - & 70\end{array}$

\begin{tabular}{ccrr}
\multicolumn{5}{c}{ Cows 2-7 (5.58 g.) } & \\
$1-6$ & $0 \cdot 03$ & $0 \cdot 5$ & $11 \cdot 3$ \\
$7-10$ & $4 \cdot 35$ & $\mathbf{7 9 \cdot 8}$ & $123 \cdot 0$ \\
$11-20$ & $0 \cdot 11$ & $2 \cdot 0$ & $90 \cdot 0$ \\
$21-30$ & $0 \cdot 41$ & $7 \cdot 5$ & $36 \cdot 3$ \\
$31-41$ & $0 \cdot 35$ & $6 \cdot 4$ & $67 \cdot 6$ \\
$42-48$ & $0 \cdot 20$ & $\mathbf{3 \cdot 8}$ & $\mathbf{4 9 \cdot 7}$
\end{tabular}

* Including very small amounts used in Liebermann-Burchard tests.

formed viscous, orange-yellow oils, fractions $D$ were semi-solid and virtually colourless, fractions $E$ gave rosettes of pale-yellow crystals and fractions $F$ formed yellow or pale-brown oils. As already mentioned, free higher fatty acids, when present, are eluted along with glycerides; accordingly, fractions $D$ (Table 2) were analysed for their content of glycerol and fatty acids. Fractions $D$ from cow 1 and cows 2-7 had fatty acid:glycerol ratios of 3.2:1 and 2.85:1 respectively, indicating that they consisted essentially of triglycerides; glycerol was detected, but only in trace amounts, in fractions $B$ and $E$. Free acidity was found titrimetrically in fraction $D$ from cow 1 , though none was present in the corresponding fraction of the lipids from cows $2-7$.

The iodine values of the total recovered lipids, calculated from the iodine values of the individual (pooled) lipid fractions (see Table 2) were $94 \cdot 7$ and 109.0 respectively as compared with 99.0 and 115.5 determined directly before chromatography on the lipids of cow 1 and cows 2-7 respectively.

After the completion of the chromatography the columns were each washed with 11. of ethermethanol $(1: 1, v / v)$; in neither case was more than $25 \mathrm{mg}$. of dark-yellow, apparently oxidized, oil removed accompanied by very fine particles of silica. Since surprisingly small amounts of phosphorus-containing lipids were found in the plasma extracts, the protein residue in each case was exhaustively extracted with hot chloroformmethanol $(1: 1, \mathrm{v} / \mathrm{v})$. These extracts yielded about $0.5 \mathrm{~g}$. of soluble matter, of which only about $10 \%$ was subsequently soluble in chloroform alone. This chloroform-soluble material was a viscous, darkbrown oil having a phosphorus content of approximately $0 \cdot 1 \%$.

As already indicated, the major component ( $\beta$ carotene) of the coloured substances present in the plasma lipids was eluted along with the main sterol ester fraction, and a second yellow band accompanied the sterols. Among other minor coloured zones observed was a pale-pink band which ran ahead of the $\beta$-carotene zone, but which became very diffuse during elution of the column with $1 \%$ ether in light petroleum. A pale-green band remained almost at the top of the column until it was eluted with ether-methanol.

\section{DISCUSSION}

The method of chromatography employing light petroleum-ether mixtures for the elution of adsorbed lipids from silicic acid columns (Fillerup \& Mead, $1953 a, b)$ was chosen in preference to the procedure of Borgström (1952b), in which benzene is a component of the eluting solvent, since we wished to avoid any possible interference with spectrophotometric analysis in subsequent studies of fatty acid composition. It is noteworthy that laboratory preparations of silica gel proved to be unsatisfactory, again demonstrating the variability of this material as an adsorbent (cf. Lovern, 1956).

Though it is not claimed that completely homogeneous classes of compounds were obtained chromatographically, it is evident from the analytical 
data that the sterol esters, glycerides, free sterols and phospholipids were separated from each other. The Liebermann-Burchard reaction showed that only those column fractions which were pooled to give lipid fractions $B$ and $E$ (Table 2) contained cholesterol, and quantitative studies showed that all the cholesterol in fractions $B$ was esterified, whereas that in fractions $E$ was free. Fractions $C$, which represented only a very small proportion of the total lipids, contained, inter alia, an esterified sterol or sterols which reacted with the LiebermannBurchard reagents. Triglycerides were present almost exclusively in fractions $D$. Organic phosphorus was found for the most part in fractions $F$, which doubtless also contained non-lipid material.

The fatty acid composition of the sterol esters and triglycerides from cows 2-7 (see Lough et al. 1957) will be discussed in the following paper. An investigation to establish the nature of the sterols, other than cholesterol, which may be present in fractions $B, C$ and $E$, is being undertaken; it is possible that higher aliphatic alcohols, such as were found by Lovern (1956) in the lipids of haddock flesh, may also be present.

In Table 3 the component lipids extracted from the bulked sample of plasma of the six pasture-fed, lactating animals are compared with those calculated from the results of Kelsey \& Longenecker (1941), who obtained their lipids from six similar cows. The extraction procedure used to isolate the lipids was apparently similar in both cases though, as already indicated, the subsequent analysis was carried out by totally different methods. Both our results and those of Kelsey \& Longenecker (1941) serve to emphasize the preponderance of sterol (cholesterol) esters in the plasma lipids of the lactating cow and the relatively small proportions of triglycerides and free sterols which are present. Whereas Channon \& Collinson (1929) could not detect free fatty acids in the plasma lipids of lactating cows, our preparations did contain small amounts

Table 3. Analysis of lipids extracted from the plasma of lactating, pasture-fed cows

Figures are expressed as percentage by wt. of total lipids.

$\begin{array}{lcc} & \begin{array}{c}\text { Present } \\ \text { work } \\ \text { (cows 2-7) } \\ (\%)\end{array} & \begin{array}{c}\text { Kelsey \& } \\ \text { Longenecker } \\ (1941)\end{array} \\ & 79 \cdot 8 & (\%) \\ \text { Sterol (cholesterol) esters } & 7 \cdot 5 & 54 \cdot 1 \\ \text { Triglycerides } & 6 \cdot 4 & 9 \cdot 6 \\ \text { Sterols (cholesterol) } & 3 \cdot 8^{*} & 11 \cdot 9 \\ \text { Phospholipids } & \text { Traces } & 13 \cdot 8 \\ \text { Free fatty acids } & 2 \cdot 5 & -10 \cdot 6 \\ \text { Unidentified lipids } \dagger & & \\ \text { * Includes non-lipid material. } & \\ \text { † Fractions } A \text { and } C \text { (Table 2). }\end{array}$

of acidic components, though much less (especially in the lipids of cows 2-7) than were found by Kelsey \& Longenecker (1941), who reported the presence of some $10 \%$ (mainly palmitic, oleic and linoleic acids) in their material. These free acids may have been derived, as the work of Schaible (1932) suggests, from the decomposition of phospholipids during the extraction procedure.

Though we were not primarily interested in the isolation of phospholipids, it is noteworthy that the amounts of lipid phosphorus reported by Kelsey \& Longenecker (1941) and by other workers, e.g. Maynard, McCay, Ellis, Hodson \& Davis (1938), were considerably greater than those found in either of our lipid extracts. In our work the ethanolether extracts were concentrated rapidly under reduced pressure on a hot-water bath (temperature about $80^{\circ}$ ) and it is possible that some phospholipids were thereby rendered insoluble in light petroleum (cf. Ellis \& Maynard, 1937); another possibility, perhaps more likely, is that phospholipids remained in the aqueous ethanol after extraction with light petroleum. In further studies this will be investigated in more detail, though it may be mentioned that, with essentially the same procedure as we have used for cow-plasma lipids, the plasma lipids of lactating sheep were found to contain 17-25\% of phospholipids (Garton \& Duncan, unpublished work).

\section{SUMMARY}

1. Lipids, prepared by ethanol-ether extraction of the plasma of lactating cows, were extracted with light petroleum. The lipids soluble in light petroleum were subjected to chromatography on silicic acid columns.

2. Fractions were obtained which consisted essentially of sterol esters (the main component of the extracts), of triglycerides and of free sterols; other smaller fractions consisted of unidentified lipids and of phospholipids which were accompanied by non-lipid material.

We wish to thank Mr J. V. Evans for taking the blood samples and Dr A. K. Lough for the cholesterol and glycerol analyses.

\section{REFERENCES}

Berenblum, I. \& Chain, E. (1938). Biochem. J. 32, 295.

Borgström, B. (1952a). Acta physiol. scand. 25, 101.

Borgström, B. (1952b). Acta physiol. scand. 25, 111.

Channon, H. J. \& Collinson, G. A. (1929). Biochem. J. 23, 663.

Clément, G., Clément-Champougny, J. \& Louedec, A. (1954). Arch. Sci. physiol. 8, 233.

Desnuelles, P., Naudet, M. \& Rouzier, J. (1948). Biochim. biophys. Acta, 2, 561 . 
Ellis, G. \& Maynard, L. A. (1937). J. biol. Chem. 118, 701.

Fillerup, D. L. \& Mead, J. F. (1953a). Proc. Soc. exp. Biol., N.Y., 83, 574.

Fillerup, D. L. \& Mead, J. F. (1953b). Atomic Energy Project Report, 251. University of California, Los Angeles.

Folley, S. J. (1956). The Physiology and Biochemistry of Lactation. Edinburgh: Oliver and Boyd.

Gordon, A. H., Martin, A. J. P. \& Synge, R. L. M. (1943). Biochem. J. 37, 79.

Gordon, A. H., Martin, A. J. P. \& Synge, R. L. M. (1944). Biochem. J. 38, 65.

Kelsey, F. E. (1939). J. biol. Chem. 130, 187.

Kelsey, F. E. \& Longenecker, H. E. (1941). J. biol. Chem. 139, 727.

Korn, E. D. (1955). J. biol. Chem. 215, 1.

Lambert, M. \& Neish, A. C. (1950). Canad. J. Res. 28, 83.
Lough, A. K., Garton, G. A. \& Duncan, W. R. H. (1957). Biochem. J. 65, 31 P.

Lovern, J. A. (1956). Biochem. J. 63, 373.

Maynard, L. A., McCay, C. M., Ellis, G. H., Hodson, A. Z. \& Davis, G. K. (1938). Mem. Cornell agric. Exp. Sta. no. 211.

Mead, J. F. \& Fillerup, D. L. (1954). Proc. Soc. exp. Biol., N.Y., 86, 449.

Morton, R. A. (1942). The Application of Absorption Spectra to the Study of Vitamins, Hormones and Coenzymes, 2nd ed. London: Adam Hilger.

Savary, P. \& Desnuelles, P. (1956). Biochim. biophys: Acta, $21,349$.

Schaible, P. J. (1932). J. biol. Chem. 95, 79.

Schoenheimer, R. \& Sperry, W. M. (1934). J. biol. Chem. 106, 745.

Trappe, W. (1938). Biochem. Z. 296, 180.

\title{
Blood Lipids
}

\section{PLASMA LIPIDS OF THE LACTATING COW: FATTY ACID COMPOSITION OF THE STEROL ESTERS AND TRIGLYCERIDES}

\author{
By A. K. LOUGH and G. A. GARTON \\ Rowett Research Institute, Bucksburn, Aberdeenshire
}

(Received 13 March 1957)

Since the triglycerides and possibly the sterol esters of blood plasma are involved in milk-fat formation in the cow (see review by Folley, 1956), it is of considerable biochemical interest to study the fatty acid composition of these classes of lipid, especially in relation to the fatty acid composition of dietary, depot and milk fats. The only information concerning the component fatty acids of the plasma lipids of lactating cows is that obtained by Kelsey \& Longenecker (1941), who determined by ester fractionation the composition of the triglycerides, sterol esters and free fatty acids. However, as discussed by Lovern (1956) and Garton \& Duncan (1957), it seems doubtful whether the cholesterol esters and triglycerides were effectively separated from each other by the procedure employed, namely selective enzymic hydrolysis of the glycerides. In this laboratory we preferred to use the more recently developed technique of chromatography on silicic acid (Fillerup \& Mead, 1953) to separate the sterol esters and triglycerides from the plasma lipids of lactating cows (Garton \& Duncan, 1957), and in this paper we describe the determination, on a semi-micro scale, of the fatty acid composition of these classes of lipid by means of reversed-phase partition chromatography. A preliminary account of this work has been published (Lough, Garton \& Duncan, 1957).

\section{EXPERIMENTAL}

\section{Preparation of fatty acids}

The sterol esters and triglycerides used were those prepared by chromatography on silicic acid by Garton \& Duncan (1957) from the pooled plasma lipids of six lactating, pasture-fed Ayrshire cows. The sterol esters obtained chromatographically were hydrolysed with ethanolic KOH to yield pale-yellow, liquid fatty acids having an iodine value (Trappe, 1938) of 189.5; the triglyceride fraction was similarly treated to give almost colourless, solid fatty acids of iodine value $36 \cdot 3$.

\section{Estimation of polyethenoid fatty acids by alkali isomerization}

Samples of the sterol-ester fatty acids and the glyceride fatty acids were examined according to the method of Hilditch, Patel \& Riley (1951), which is applicable to linoleic and linolenic acids but is not applicable in the presence of arachidonic acid in significant amounts. The presence of arachidonic acid is indicated by $\lambda \lambda_{\max } .301$ and $315 \mathrm{~m} \mu$; none was detected in the glyceride fatty acids, but appreciable amounts were present in the sterol-ester fatty acids. Accordingly, extinction coefficients for this acid (not available to us in a pure form) were derived from the data given by Brice, Swain, Herb, Nichols \& Riemenschneider (1952), who carried out alkali-isomerization studies with arachidonic acid under similar conditions to those used by Hilditch et al. (1951). These values, after isomerization at $180^{\circ}$ for $60 \mathrm{~min}$., were taken as $E_{1 \mathrm{~cm}}^{1 \%}$ at $315 \mathrm{~m} \mu=201$, and 